\title{
علم الصرف، نظرياته وتطوراته والاستفادة منه في تعليم اللغة العربية
}

\author{
Akhsan Akhsan $^{1}$, Ahmadi Muhammadiyah ${ }^{1}$, Wahyudin Wahyudin ${ }^{2}$, Zulli Umri $^{3}$ \\ ${ }^{1}$ Univesitas Ibrahimy Situbondo \\ ${ }^{2}$ IAIN Syekh Nurjati, Cirebon \\ ${ }^{3}$ UIN Sunan Gunung Jati Bandung \\ ${ }^{1 *}$ ahsanthayyib@gmail.com
}

\begin{abstract}
Sharf is one of the most important branches of knowledge in Arabic, by which a learner can know and understand the form of a word, its origin, its changes, and its meaning, so that it is hoped that he will be able to understand the Arabic text he reads and hears. The substance of the Sharf is to discuss the forms of words with the aim of knowing the meaning of each of these word changes. The goal of learning Sharaf is to teach students about changes in the form of a word to another word to find out its true meaning. Sharf science is one of the scientific principles in Arabic which is one of the media (intermediaries) to master language skills. Therefore, the Sharf should be taught by paying attention to the following matters: 1) Teaching the Sharf science is not a goal (learning the science of Sharf for the Sharf) but as a instrumen (tool) to get competence and language skills, 2) Teaching the Sharf requires a lot of practice and not only focus on teaching the rules and forgetting the basic function, 3) it must be taught in stages according to the students' abilities, for example from Mujarrad to Mazid and practice in perfect sentences (Jumlah Mufidah).
\end{abstract}

\section{الكلمة الأساسية: نظرية علم الصرف، استفادة علم الصرف، تعليم اللغة العربية}

$$
\begin{aligned}
& \text { إلى هدفه، فإن لكل علمٍ هدفا، والهدف الأهم لكل } \\
& \text { علم هو فهمه والعملُ به، وخير ما يححق هذه الغاية } \\
& \text { هي الكتابة، لأكا تقيد العلم وتحفظه. ولذا، تكتب } \\
& \text { هذه الورقة البحثية أو المقالة البسيطة سعيا للحصول } \\
& \text { على فهم ما يتعلق به من مفهوم علم الصرف، } \\
& \text { تطورات ونظرياته ثم الاستفادة منه في بحالات تعليم }
\end{aligned}
$$

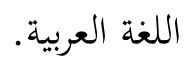

$$
\begin{aligned}
& \text { ولقد فهم القدماء علم الصرف فهما } \\
& \text { صحيحا حين جعلواه مع النحو علما واحدا، أو } \\
& \text { حين أشار بعضهم إلى ضرورة دراسته قبل النحو على } \\
& \text { ما قرر أبو الفتح إبن جني في شرحه على تصريف } \\
& \text { إبن عثمان. غير أن الكتب القديمة التي أفردها }
\end{aligned}
$$

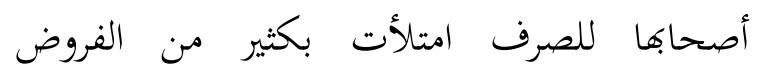

$$
\begin{aligned}
& \text { والتمرينات التي يبلغ بعضها درجة الحيل والألغاز، مما }
\end{aligned}
$$

$$
\begin{aligned}
& \text { من المعلوم أن للّغة العربية علوم متنوعة } \\
& \text { ومنها علم النحو، وعلم الصرف، وعلم البلاغة، } \\
& \text { وعلم الأصوات، وعلم الدلالة وما إلى ذلك. فلكل } \\
& \text { منها وظيفتها في اللغة حيث يتعلق بعضها بعضا } \\
& \text { ولاينفصل في تطبيقاتا. } \\
& \text { فعلم الصرف هو علم من علوم اللغة } \\
& \text { العربية المهمة التي له أهميته وفوائده لدي المتكلم } \\
& \text { والمتعلم خاصة ودارسي اللغة عامة، إذ لا يستغني عنه } \\
& \text { طالب العلم؛ لما له من أهمية وفضل، ويكفي في } \\
& \text { فضله أن جزءاكبيرا من اللغة يتوقّف عليه، لأن كثيرا } \\
& \text { من اللغة يؤخذ بالقياس وما يتوصل إلى القياس إلا } \\
& \text { بعلم الصرف. ولذا كان هذا العلم محل عناية من } \\
& \text { العلماء على مر العصور. فاعتنوا به حتى يصلوا فيه }
\end{aligned}
$$


استخدم هذا البحث بحثا مكتبيا، ومن

خلال هذا البحث بحث الباحثون المصادر ذات الصلة وقاموا بالتحليل واستنتاج الوصف النظري ثئم

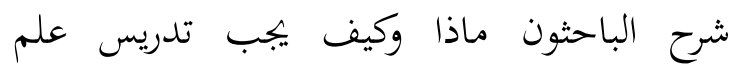
الصرف في بحال تدريس اللغة العربية ليستفيد منه تئه

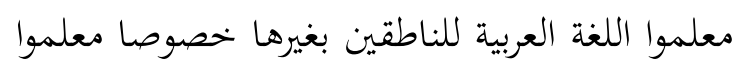

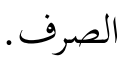
تحليلها ومناقشها

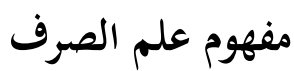

قيل أن المعنى العام الذي يدور لكلمة "صرف" في اللغة على ثلاثة معان وهي، التحويل،

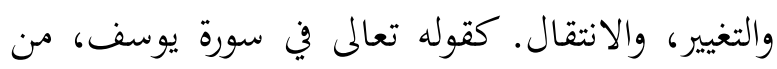
الاية 32:"فاستجاب له ربّه فصرف عنه كيدهنّ، إنه

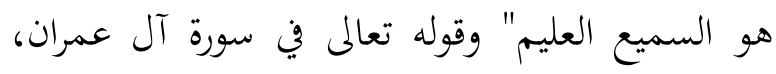
من الاية 152: "...ثم صرفكم عنهم ليبتليكم.."

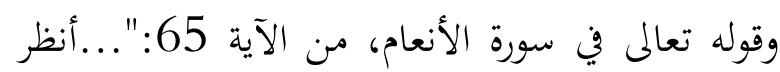
كيف نصرف الآيات لعلكم يفقهون."وقوله تعالى في

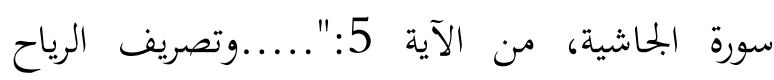
أيات لقوم يعقلون"3 الجية،

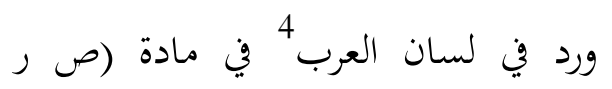

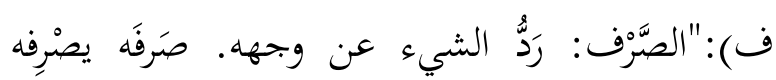

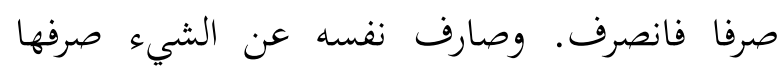

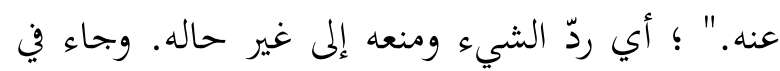

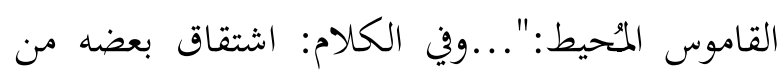

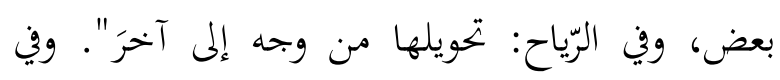

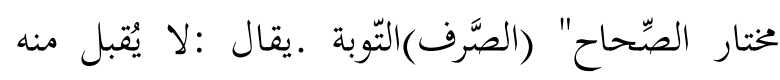

3 حسان بن عبد الله الغنيمان، الواضح في الصرف. مالك بن سعود مكة المكرومة دون السنة. ص. 10 4إبن منظور، لسان العرب (صرف) 91:11. دار المعارف
يجعلها عسيرة الفهم من ناحية، ومشكوكا في جدواها من ناحية أخري. 1

فلهذا العلم كما رأى ابن جني له أهمية

كبيرة من بين علوم العربية، حيث قال "إنك لا لا لهائ تكاد تجد كتابا في النحو إلا والتصريف في آخره. فالتصريف إنما هو لمعرفة أنفس الكلم الثابتة،

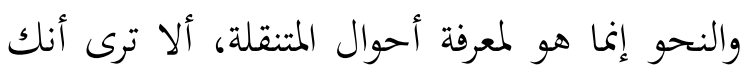

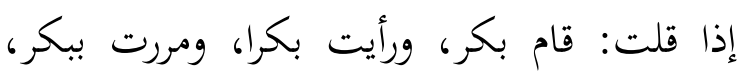
فإنك إنما خالفت بين حركات حروف الإعراب لاختلاف العامل، ولم تعرض لباقي الكلمة. وإذا كان كذلك فقد كان من الواجب على من أراد

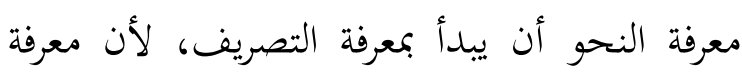
الشيء الثابتة ينبغي أن يكون أصلا لمعرفة حال المتنقلة

ولكن كثير من المدارس والمعاهد خصوصا في إندونيسيا يدرّس هذا العلم معزولة من اللغة العربية

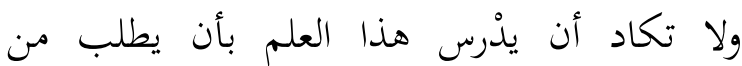

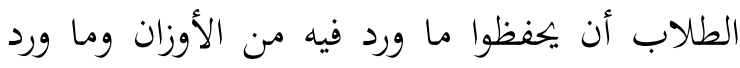
من التصريف اللغوي والإصطلاحي والإعلال مما هو العال صعب للطلاب الناطقين بغير اللغة العربية . إنطلاقا مما سبق، هدف هذا البحث للوصف وللكشف عن علم الصرف من حيث 1) اهداف تدريس علم الصرف و 2) تطورات علم الصرف ونظرياته، و3) الاستفادة منه لتعليم اللغة العربية.

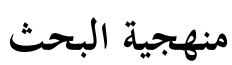
1 عبده الرابحي. التطبيق الصرفي، دار المعرفة المامعية: إسكندرية- بيروت

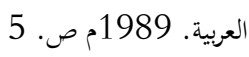
22 ابن جني : المنصف في شرح كتاب التصريف............. 2: 2 
إعلال، ومن إبدال أو حذف أو إدغام أو إمالة، وما

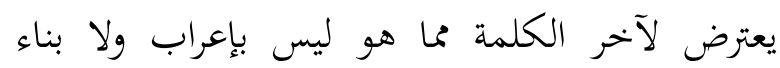

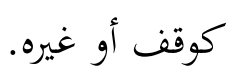

الصرف هو البحث في أحوال الكلم

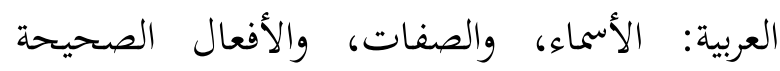

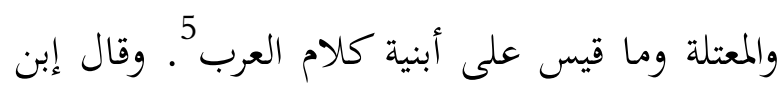
جنى، الصرف هو تحويل الكلمة إلى أبنية مختلفة لضروب من المعاني كالفعلية، والوصفية، والتصغير،

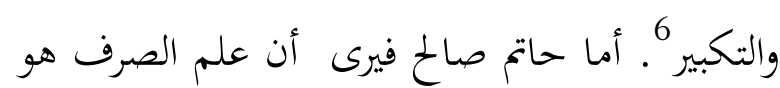

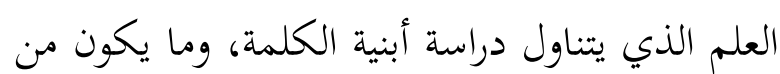

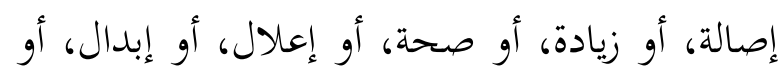

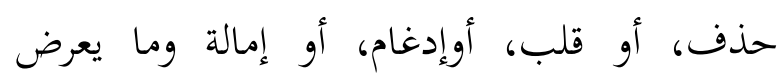
لآخرها مما ليس بإعراب ولا بناء كالوقف وغيره. 7

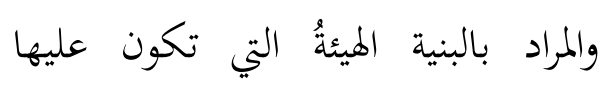

الكلمة، والتي تتركب من عدد حروف الكلمة، وكيفية تركيبها في شكلها الإفرادي، وكذا حركاتا وسكونها.

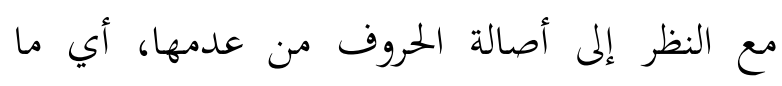

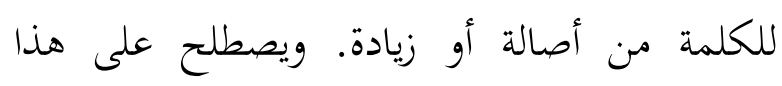
المفهوم أيضا: البناء، والصيغة، والوزن، والزنة. وأما

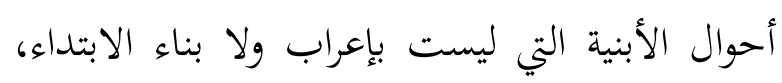
والإمالة، والتخفيف، والهمزة، والإعلال. موضوع علم الصرف وميدانه

5 كسن هيداوي، مناهج الصرفيين ومذاهبهم في القرن الثالث والرابع من

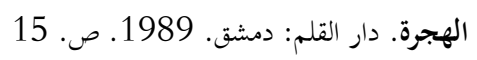
6 إبن جنى، الخصائص، عالم الكتب: بيروت. ط. 3. 3.

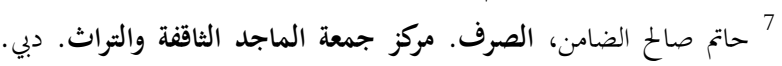

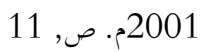

صرْف و لا عذْل ... و صَرفُ الدهر حدثانه و نوائبه « ؛لأن التائب يتغير من حال العصيان و الفسوق إلى صلى

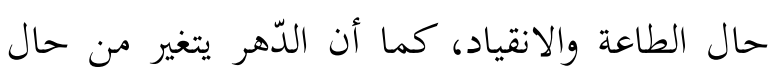

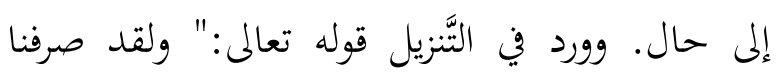

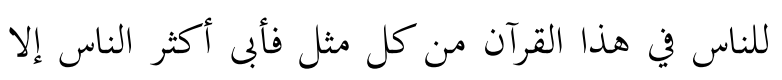

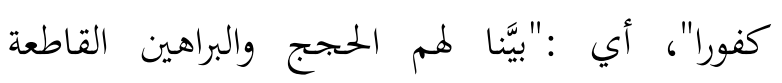
ووضَّحنا لهم الحق وشرحناه" .فتصريف الآيات تببينها.

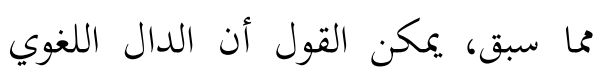

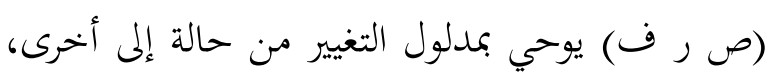

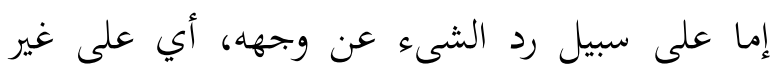

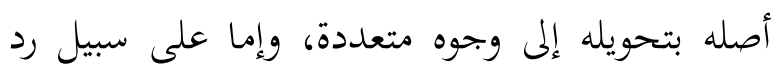
الشيء ومنعه، وقد يرد بمعنى التبّيين والإيضاح.

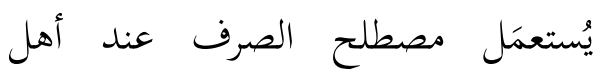

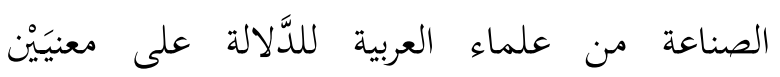

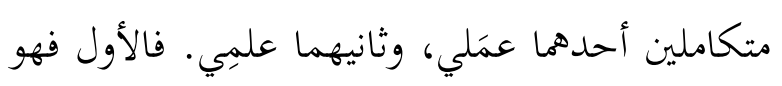

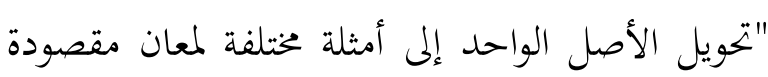

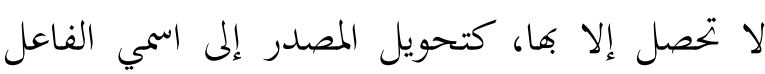

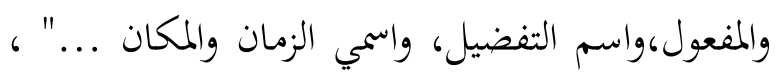

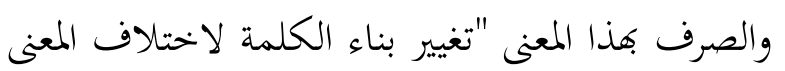
المراد كتغيير ضَرَب إلى يضْرِب،وإلى إضْراب، وتغنيير

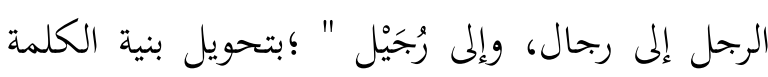

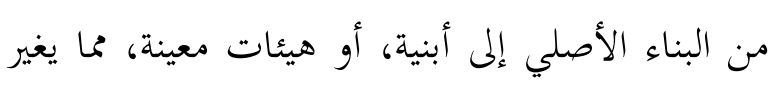
من الدَّلاة. إذ إن التغيير في البنية تغيير في المعنى: كرجل إلى رجال دلالة على الجمع، وإلى رُبحيّل دَلالة على التصغير. وأما الثاني فهو العِلم "الذي يبحث في اللفظ المفرد من حيث بناؤه ووزنه، وما طرأ على هيكله لمانه

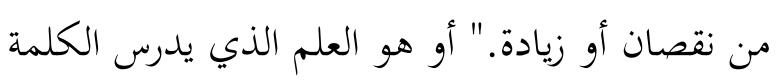

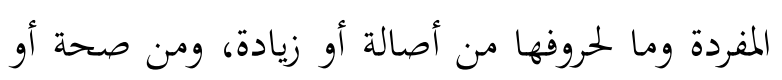


من هذا أنه لا يتطرق إلى الحرف والاسم المبني، وكذا الفعل الجامد؛ ومردٌٌ ذلك "أن الحروف بحهولة الأصل فهي كالأصوات نهو: صه، ومه، ونحوها، فالحروف لا

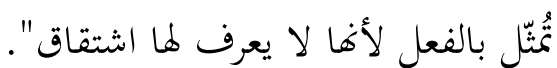
أهمية علم الصرف:

عرف القدماء من العلماء العرب أهمية علم الصرف؛ لذلك نبهوا على احتياج جميع المشتغلين باللغة العربية إليه، فهو ميزان العربية الذي نستطيع عن طريق التعرف على بنية الكلمة وحروفها الأصلية، وما أصابها من التغيير. وقد قال أبو فتح عثمان بن جني في فضائل هذا العلم: "التصريف يجتاج إليه جميع أهل العربية أتم حاجة، وبهم إليه أشد فاقة؛ لأنه ميزان العربية، وبه إله

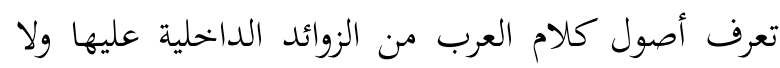

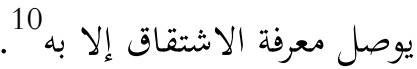

ولعلم الصرف أهمية كبيرة من بين علوم

العربية، فهو أهم من علم النحو؛ قال ابن جني "إنك لا تكاد بتحد كتابا في النحو إلا والتصريف في آخره. فالتصريف إنما هو لمعرفة أنفس الكلم الثابتة، والنحو إنما هو لمعرفة أحوال المتنقلة، ألا ترى أنك إذا قلت

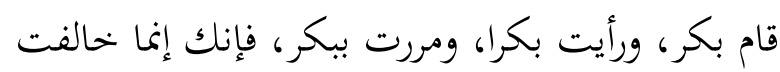
بين حركات حروف الإعراب لاختلاف العامل، ولم تعرض لباقي الكلمة. وإذا كان كذلك فقد كان من الواجب على من أراد معرفة النحو أن يبدأ بمعرفة التصريف، لأن معرفة الشيء الثابتة ينبغي أن يكون أصلا لمعرفة حال المتنقلة 11

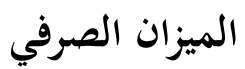

10 10 جني : المنصف في شرح كتاب التصريف للمازني: 1: 2 11 1بن جني : المنصف في شرح كتاب التصريف........ 2: 2
قال حاتم:"

المفردات العربية من حيث البحث عن كيفية صياغتها لإفادة المعاني، أو من حيث البحث عن أحوالها العارضة لها من صحة وإعلال، ونحوهما. والمراد بالمفردات العربية هنا؛ الاسم المتمكن، والفعل المتصرف دون ماعداهماز فالحروف بجميع أنواعها، والاسم المبنى، والأفعال الجامدة لايبري البحث عنها في علم الصرف. وموضوع الصرف يتكون من الأبنية وأحوالها : الأبنية هي التغييرات التي تطرأ على البنية، في هذا القسمتحدث فيه معاني جديدة، فكل تغيير يولد بنية تختلف عن سابقتها في المعنى والمبنى. فتدرس هنا أنواعا مختلفة من الأبنية، كل نوع يتميز بخصائصه المعنوية الشكلية. وأما أحوال الأبنية فالتغييرات التي تطرأ على البنية، ويي هذا القسم لاتنقلها من نوع إلى أخر، ولاتكسبها دلالة جديدة، إنما هي تغييرات شكلية، وظراهر صوتية عامة تطرأ على البنية أيا كان نوعها اسما أو فعلا، أو حرفا. مما سبق يمكن القول إذا كان النحو يبحث في الجملة العربية من حيث تركيبُها، فالصرف يبحث في الكلمات العربية حالة إفرادها وفق وزنات معينة. وموضوع الصرف "أبنية المفردات العربية من حيث صياغتها لإفادة المعاني المختلفة، وما يعتريها من الأحوال العارضة، كالصحة، و والإعلال، والإمالة، والزيادة و نهوها." وأما ميدانه وبحاله فيختص بالأسماء المتمكنة، والأفعال المتصرفة دون غيرها؛ "لأنّ ما عدا ولها ذلك قوالب ثابتة لا يدخلها تغيير ولا تبديل." ويفهم

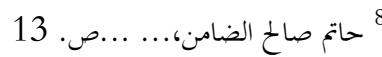
9 لطيفة إبراهيم النجاري، دور البيئة الصرفية وصف الظف الظاهرة النحوية

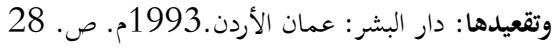


أصبحت يَنَوْمُ (بالنقل) ثنم ينام

(بالقلب)، 4) الإعلال بالإدغام،مثل شدّ أصلها شدد، سكنت اللام الأولى

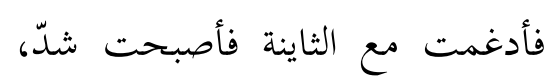

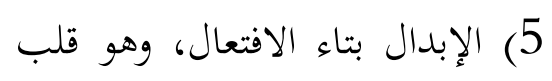
تاء الافتعال دالا أو طاء. مثل إزْدَجرَ

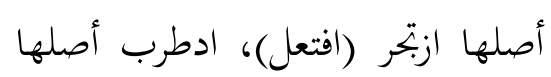
ادترب (افتعل).

ب) الإعلال الذي يراعي في الميزان : 1 1أنعل)

الإعلال بالحذف، مثل يَِقِفُ أصلها

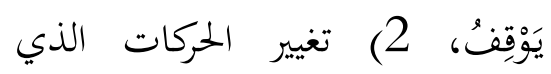
يحدث في بعض لغات العرب، مثل

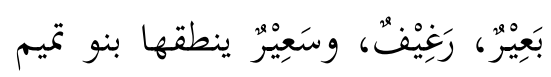

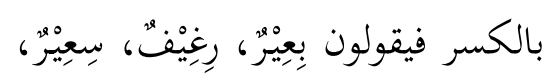

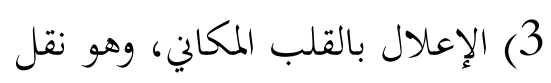
حرف مكان حرف آخر، مثل أشياء

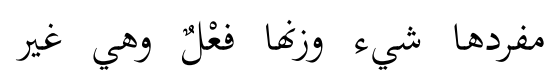

$$
\text { الثاني. وزن الكلمة المزيدة: }
$$

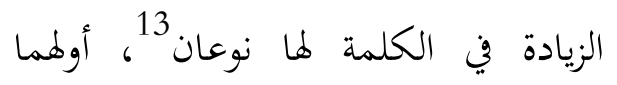

زيادة بالتضعيف يعني بتكرار أحد أحرف الكلمة

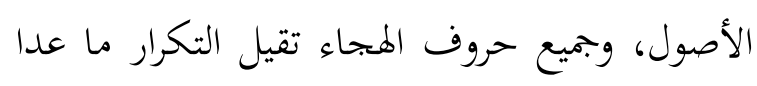

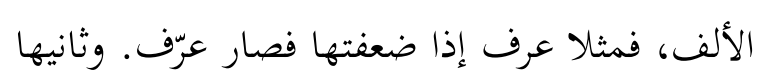

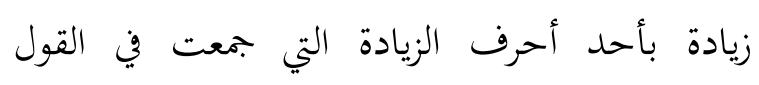

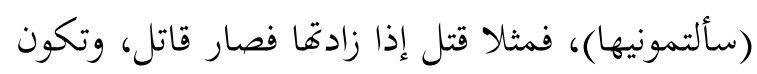

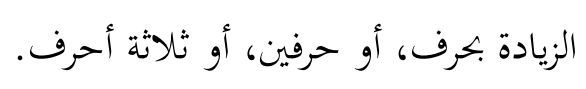

$$
\text { تطورات علم الصرف }
$$

13

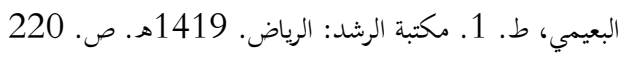

اختزع علماء الصرف مقياسا يقاس به التعبير

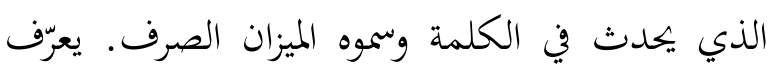

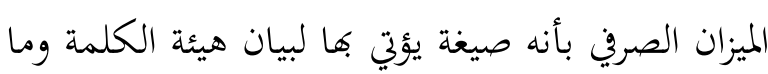

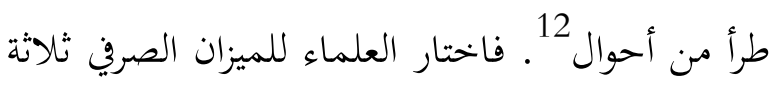
أحرف هي: الفاء، والعين، واللام، يجمعها القول:

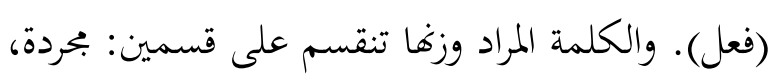

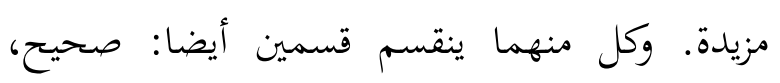
ومعتل، وكل من هذه الأقسام طريقة في الوزن.

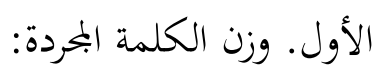

1- وزن الكلمة المجردة الصحيحة، ويتكون من وزن الكمدة:

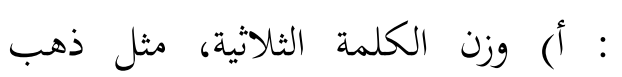

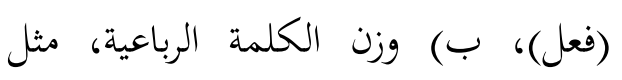
دخرج (فعلل)، ج) وزن الكلمة الخماسية، ونية مثل سفرجل (فعلّل) 2- وزن الكلمة المجردة المعتلة : أ) الإعلال الذي لايراعي في الميزان وهو المعان

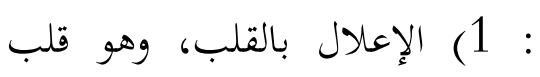
حرف العلة حرف علة آخر،م مثال

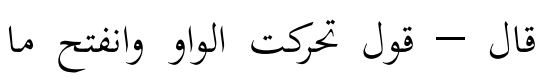

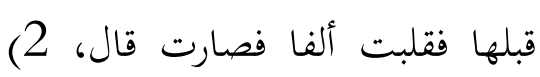
الإعلال بالنقل، وسمي الإعلال

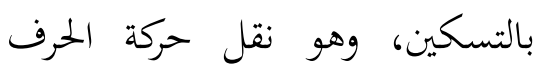
المعتل إلى الحرف الصحيح الساكن

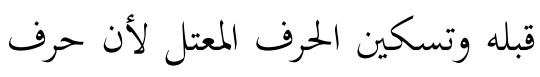
المعتل الضعيف فلايقوي حمل الحركة.

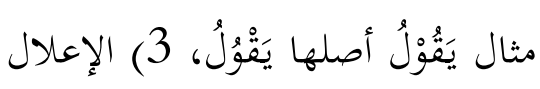

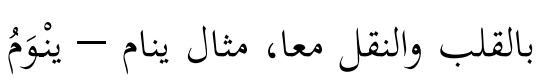

12 إبن مالك، شرح الكافية الشافية. تحقيق الدكتور عبد المنعم أممد هريدي.

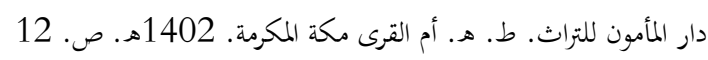


هنا كان الحاجة الاجتماعية قائمة لظهور علم لقواعد اللغة العربية، ومما يدل على هذا بروز كثير من الموالي في علوم العربية وتفوقهم فيه.

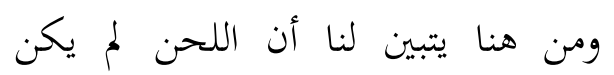

السبب الرئيسي لظهور علم النحو والصرف، وإنما هو داخل ضمن الحاجة الدينية والاجتماعية، لأن اللحن يفسد المعنى فإذا لحن المتكلم وهو يقرأن القرآن الكريم أو حديث الرسول كان لحنه داخل ضمن الحاجة الدينية، وإذا لحن في غيرهما من الكالام كان لحنه داخل ضمن الحاجة الاجتماعية، إضافة إلى أن المتكلم عندما

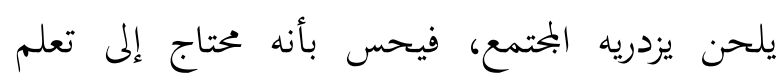

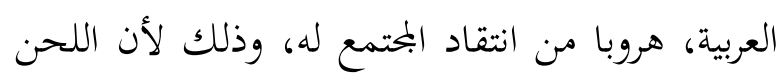
مذموم لديهم ومستقبح عندهم.

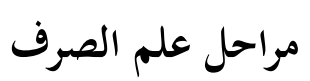

مر علم الصرف بل والنحو في أربع مراحل هي: المرحلة الأولى: مرحلة النشوء. تبدأ هذه المرحلة من سنة 40 هـ إلى سنة 154 هـ، وقامت هذه المرحلة في البصرة وها طوران: الطور الأول: اتسم هذا الطور باختلاط علم النحو والصرف وعلم القراءات، وعدم ظهور حركة التصنيف لاعتمادهم على المحفوظ في

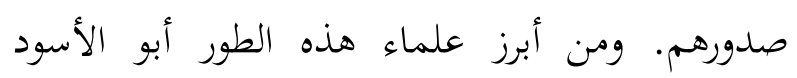
الدؤلي (69هـ)، وتلاميذه: نصر بن عاصم الليثي (89 هـ)، وعنبسة الفيل (1000 هـ)، وعبد الله بن أبي إسحاق الحضرمي (117 هـ) وعبد الرممن بين هرمز (117ه). والطور الثاني: اتسم هذا الطور بانفصال علم القراءات عن علم النحو والصرف واتساع علم النحو والصرف وظهور حركة التصنيف فيه. ومن أشهر علماء هذا الطور عيسى بن عمر القفي (149هـ) وأبو
لم يكن علم النحو والصرف معروفين في

العصر الجاهلي ولا في أوائل عصر الصحابة، وما ذاك إلا لعدم الحاجة إليها، لأهم كانوا يتكلمون العربية الفصحى بطلاقة، وعند ما انتشر الفتوح الإسلامية، دخل كثير من الأعاجم في الإسلام واختلطوا مع المسلمين العرب برزت الحاجة لعلم النحو والصرف، وكانت تتمثل فيما يلي أولا: الحاجة الدينة

قد فتح المسلمون العرب بلاد الروم وفارس

لنشر الإسلام، فدخل كثير من الأعاجم فيه، ورغبوا في تعلم أمور دينهم كي يقيموا شعائر الدين إقامة

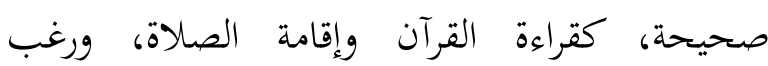
المسلمون العرب تعليمهم أمور دينهم، لأهم لم يفتحوا

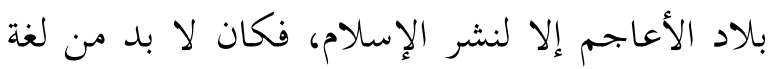
مشتركة يتفاهمون بها، ولم تكن هذه اللغة إلا اللغة

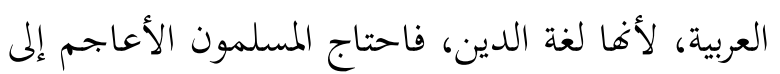
تعلم العربية، وليس بوسعهم تعلم العربية إلا بعد وضع قواعد لها، فكان لا بد من وضع قواعد للغة العربية، وهذه القواعد هي علم النحو والصرف. ثانيا: الحاجة الاجتماعية

فقد خلق الله الإنسان اجتماعيا بطبعه، ولهذا احتاج في البلاد التي فتحواها مع الأعاجم احتاجوا إلى لغة مشتركة يقضون بها حاجتهم، ولم يكن

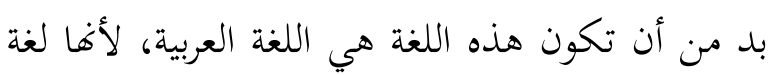
المنتصر ولغة الإسلام، ولا سبيل لاتخاذ هذه اللغة وسيلة للتعبير دون وضع قواعده لها، لتصبح هذه اللغة

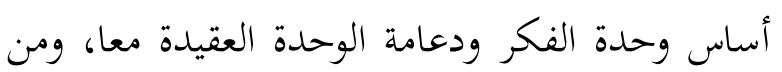
14 حسان بن عبد الله الغنيمان، الواضح في الصرف....... ص 3 
من علماء البصرة. أما علماء الكوفة فمن أشهرهم : يعقوب بن السكيت (244 هـ)، وتعلب (292 هـ) المرحلة الرابعة: مرحلة الترجيح. تبدأ هذه

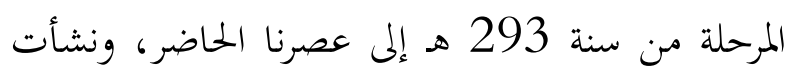
هذه المرحلة في بغداد، ثم توزعت في أقطار العالم الإسلامي. اتسمت هذه المرحلة بوجود موطن جديد لهذا العلم، وهو بغداد، وظهور مذهب جديد فيه، يقوم على أساس المفاضلة بين المذهب البصري والكويف.

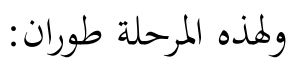

الطور الأول: طور العلماء المتقدمين،

وينتهي سنة 347 هـ، ومن علماء هذا الطور:

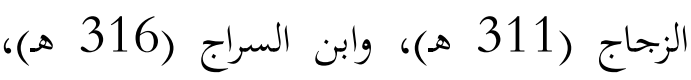

$$
\text { وابن دستويه (347 هـ). }
$$

الطور الثاني: طور العلماء المتأخرين وين

هذا الطور تفرق العلماء، وذلك بعد انتثار نظم الخلافة العباسية بتغلب بني بويه عليها سنة 334 هـ وبقاء الخالفة صورية في بغداد. مما جعلها مضطربة الأحوال، وهذه دفع العلماء إلى التفرق في أقطار العالم الإسلامي، فظهر علم النحو والصرف فب بلاد المشرق وبلاد الشام ومصر والمغرب والأندلس، فتشاطرت الدول الإسلامية هضة هذا العلم، وبعد سقوط بغداد سنة 656 هـ ظهور الحروب والفتن في العراق وبلاد المشرق نزح كثير من العلماء إلى مصر والشام. نظرا لطول مدة هذه الطور فقد تعددت مواطن هذا العلم وكثر العلماء وتنوعت المؤلفات. ومن أشهر علماء هذه الطور أبو سعيد السيرافي 0368 ه))، أبو علي الفارسي (377 هـ) الذي كتاب في الصرف سماه (التكملة)، وابن جني (392) الذي ألف أف
عمرو بن العلاء (154هـ)، اللذان كانا صاحبي تصانيف كثيرة. المرحلة الثانية: مرحلة النمو. تبدأ هذه المرحلة من سنة 155 هـ إلى سنة 220 هـ، وقامت هذه المرحلة في البصرة والكوفة. اتسمت هذه المرحلة بتعدد مواطن هذا العلم، وبكثرة العلماء، مما جعله يزدهر فظهرت مسال الخلاف، والمناظرات وكثرت المصنفات. ومن أشهر علماء هذه المرحلة: الخنليل بن أحمد الفراهيدي (175هـ)، ويونس بن حبيب (182 هـ) وسيبويه (180 هـ) الذي صنف (الكتاب) وهو أقدم كتاب نحوي وصريف يصلنا، وهو العمدة في النحو، والأخففش الأوسط (215 هـ)، وكل هؤلاء من علماء البصرة.أما الكوفة فمن أشهر علمائها في هذه المرحلة: معاذ بن مسلم الهراء (187 هـ)، وأبو جعفر الرؤاسي (190 هـ)، والكسائي (189هـ)، والفراء (207 هـ) واللحياني (220 هـ). المرحلة الثالثة: مرحلة النضوج والكمال. تبدأ هذه المرحلة من سنة 221 هـ إلى سنة 292 هـ، وقامت هذه المرحلة أيضا في البصرة والكوفة. اتسمت هذه المرحلة بنضوج عملي النحو والصرف واكتمالمما، وانفصال علم الصرف عن علم النحو. ومن أشهر علماء هذه المرحلة : أبو عمر الجرمي (225 هـ)، وأبو

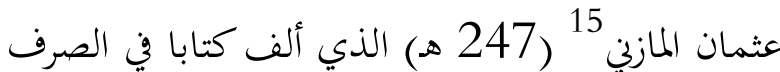
اسمه (تصريف المازين)، والمبرد (285 هـ) وجميع هؤلاء

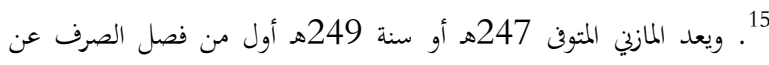
النحو فصلاً حقيقياً كاملاً ووضع فيه كتابه المعروف (التصريف)، وكانت قداند

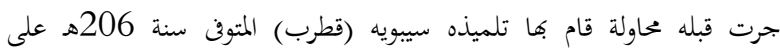

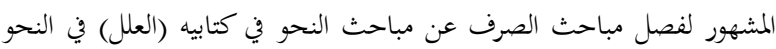

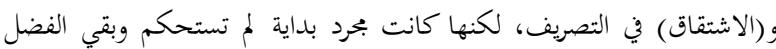

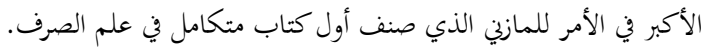


والفرعية في تراثنا اللغوي، يقول " قولهم كان الأصل كذا فاستثل، فنقل إلى كذا شيء يعلم كل ذي حس أنه كذب لم يكن قط، ولا

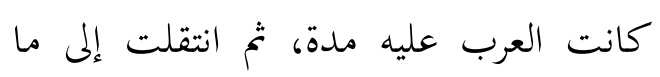
سمع عنها بعد ذلك" . وقد ورد نفي الفرعية مطلقا، وجعل بعل درل

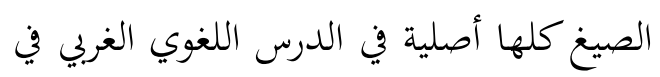

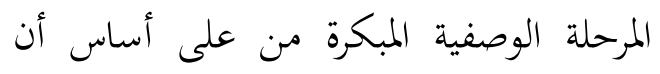

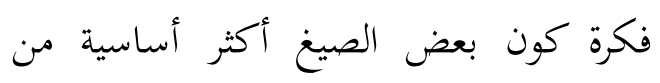
بعض فكرة.

2. أصالة بعض الصيغ وفرعية البعض الآخر

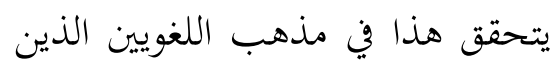

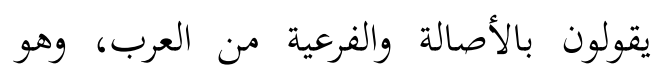

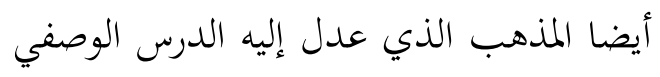
المعاصر قبل بدء المرحلة التالية.

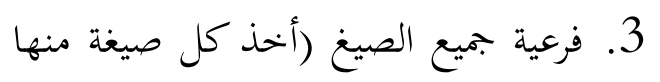

$$
\text { عن غيرها) }
$$

إن مقتضى هذا الفرض أن كل صيغة

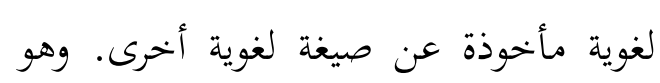
مذهب ابن حاجب. وهو في الحقيقة بحاجة

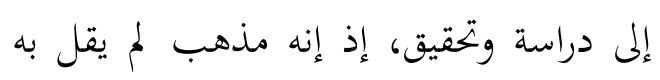
أحد غيره.

\section{ب. مناهج النظرية الصرفية للتحليل}

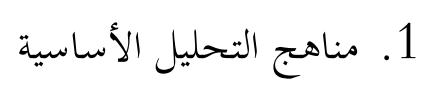

هناك ثلاثة نماذج أساسية للتحليل في الئية

الصرف العربي وهي منهج العلامة، وهي

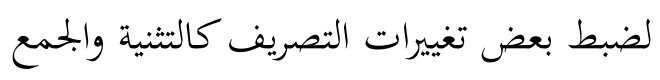
السالم، ومنهج الميزان الصريف لضبط تغييرات

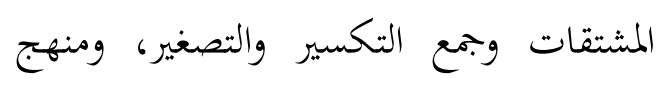

كتاب في الصرف سماه (التصريف الملوكي وسر صناعة الإعراب)، كما شرح (تصريف المازين) بشرح سماه

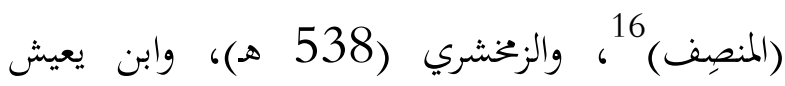

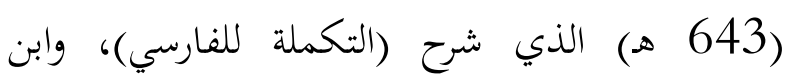
حاجب (646 هـ) الذي ألف رسالة في الصرف سماهـا

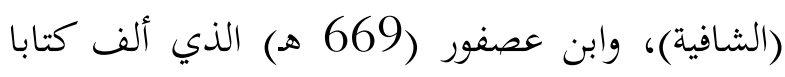

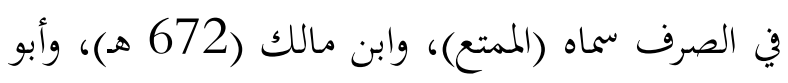

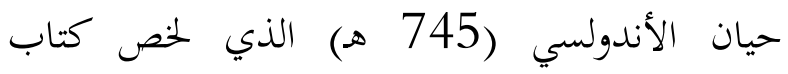
(الممتع) وسماه (المبدع)، وابن هشام الأنصاري (761 الاندي نظريات علم الصرف أ. النظرية الصرفية؛

إن موضوع الدرس الصريف ظاهرة التعدد التي

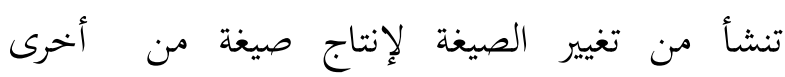
بالاشتقاق أو التصريف أو التركيب مزجيا أو عدديا.

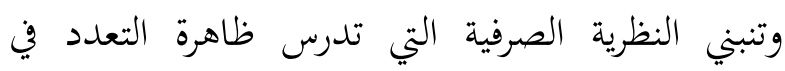

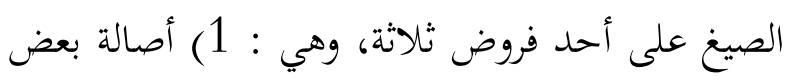

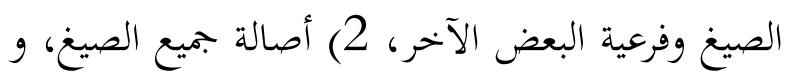
3) فرعية جميع الصيغ وفية العضن الاتر ويمكن تفصيل هذه الفروض الثلاثة على الصيغ النحو التالي : 1. أصالة جميع الصيغ دون أخذ بعضها من : بعض : لا يرد هذا الموقف في الدرس الغربي المعاصر فقط، بل يرد في كل من التراث العربي

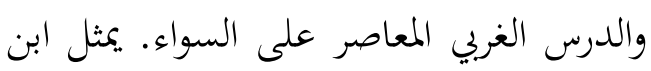
حزم أبرز الذين تبنوا نفي فكرة الأصالة

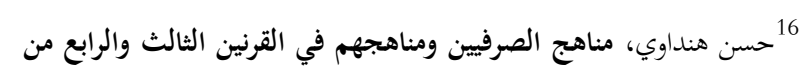
الهجرة، ...... ص. 6 
للكلمات العربية أصول اشتقاقية ثلاثة وها صيغة صرفية تختلف عن صيغ أخرى لكلمات أخرى. فلما اختلفت الصيغ و كان كل منها إطارا شكليا لعدد كبير من الكلمة أراد الصرفيون أن يرمزوا لكل حرف مه من الأصول الثلاثة برمز يعرف به موضعه

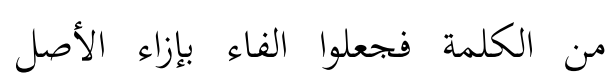
الأول والعين بإزاء الثاني وجعلوا اللام بإزاء الأصل الثالث فسموا الأول فاء الكلمة والثاني عين الكلمة والثالث لام الكلمة. فإذا كان في الكلمة حرف زائد رمزوا له وللحركات بلفظه الحقيقي وهكذا رأينا الموازين الصرفية التالية : ضرب على وزن فعل انطلق على وزن انفعل

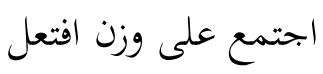
استخرج على وزن استفعل.........

$$
\text { ج) منهج جداول المبنيات الصريفية }
$$

يقوم هذا النموذج على لهع تصريفات قسم من أقسام الكلم في جدول يكشف عن أوجه التصريف شخصا ونوعا

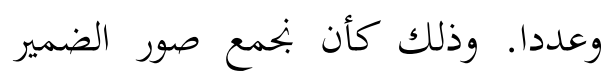
وفق الشخص متكلما ومخاطبا وغائبا , و و ؤرع وفق النوع تذكيرا وتأنيثا، و وفق العدد إفرادا وتثنية وجمعا, ووفقا لما يرد له من المواقع الإعرابية من رفع ونصب وجر . يصلح هذا النموذج في العربية لرصد تغييرات المبنيات من ضمائر و أسماء الإشارة وأسماء موصولة وأسماء شرط وأسماء
جداول التصريف لضبط تغييرات الضمير ونهوها من المبنيات. وفيما يلي حديث موجز عن هذه النماذج الثلاثة. أ ) منهج العلامة

كان هذا المنهج أحد النماذجةةة

الأساسية لتحليل التركيب الصرفي في

الدرس العربي. يقوم الصرفيون العرب من خلال هذا النموذج برصد التغييرات الصرفية التي تصاحب بعض عمليات الصرف كالتأنيث بالتاء وأ الألف، والتثنية بالألف و النون والياء و والنون وجمعي التصحيح. بعبارة أخرى، كان هذا المنهج يستخدم في العمليات الصرفية التصريفية التي تنقل الكلمة من حالة إلى حالة كعملية تغيير الاسم من التذكير إلى التأنيث، ومن الإفراد إلى التثنية أو الجممع، كما يرد كذلك في عملية النسب الصرفية 17 التي تتم بزيادة حرف النسب.

$$
\text { ب) منهج الميزان الصرفي }
$$

كان هذا المنهج يستخدم في الدرس لمراب

الصرفي العربي منذ سيبوية على رصد الجذور التي تشكل أساس الكلمات بمعنى

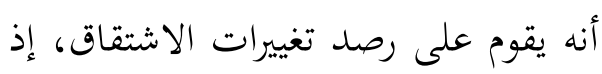

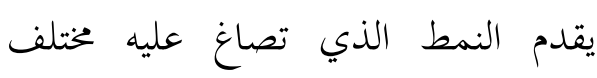
المشتقات. ومن ذلك بيانه الأوزان التي تكون عليها الأفعال ماضية ومضارعة وأمرا و المشتقات عاملة وغير عاملة. 17 محمد عبد العزيز عبد الدايم، النظرية اللغوية ... ...، ص. 162 
على الجمع من قبيل الوضع المعجمي،

ولم تستمدها من المفردات بالعملية

الصرفية المعروفة بالجمع. وكذلك الحال

$$
\text { في اسم المصدر واسم الفعل. }
$$$$
\text { ب) منهج الإلحاق }
$$

قد ورد هذا المنهج لعلاج ما يخالف

القواعد المنضبطة التي يرصدها منهجا

العلامة الصرفي و الميزا ن الصرفي. ومثال

ذلك حيث قال الصرفيون العرب بالملحق

بالمثنى والملحق بجمع المذ كر السالم

والملحق بجمع المؤ نث السالم مع ما

ظاهره أنه من قبيل التنية أو جمع

التصحيح، مع أن الحقيقة ليس كذلك

لتخلف بعض الشروط التي تضبط زيادة

العلامة. فزيادة علامة التثنية تستلزم

وجود جذع تزيد عليه العلامة. ومن ثم

يعد كلا وكلتا من الملحق بالمثنى لا من

المثنى. وكذلك الأ مر في الملحق بجمع

التصحيح.

$$
\text { ج) منهج القلب المكاني : }
$$

استخدم اللغويون العرب هذ المنهج

في تحليلهم لبعض الألفاظ التي خرجت عن منهج الأصل المتمثل في الميزان الصرفي. وذلك كما في لفظ ((أيس)) مثلا، لا يخفى ما في هذا اللفظ من خروج عن قواعد الميزان، إذ يتخلف عنه التصريفات الأخرى، فليس له مضارع ولا مصدر. كما أن فيه مخالفة في كوها جاءت على التصحيح التي تخالف قوا
استفهام حيث يجمع أفراد هذه الأصناف

ويسجل صورها مع ما يقابل كل صورة من سن

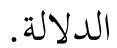

$$
\text { 2. مناهج التحليل غير الأساسية }
$$

لم تقتصر النظرية الصرفية العربية في تحليلها

للتركيب الصري على هذه المناهج الثالثة وإنما

قدمت جملة أخرى من مناهج التحليل

الصرفي. قد استخدم الصرفيون مناهج تكمل

ما يخالف المناهج الأساسية-التى سبق بياها

وتسمى بالمناهج التكميلية. وكذلك قد قدئ لـ

استخدم الصرفيون جملة مناهج أخرى مخالفة

لنوعي المنهج السابق التى تسمى بالمناهج

البديلة .

استخدمت النظرية الصرفية المناهج

التكميلية لبعض ما خرج على المنهج

الأساسى. وتتمثل هذه المناهج فيمايلي :

$$
\text { : ألاسمية الاسمئ }
$$

يمكن تسجيل هذا المنهج من خلال

مراجعة ما تقدمه النظرية الصرفية في

تحليلها لأقسام الكلم التي عرفت باسم

الجمع و اسم المصدر واسم الفعل.

ويظهر ذلك من هذا المصطلح يستخدم

عندما تتخلف الشروط اللازمة لإجراء

العملية الصرفية كالجمع أو صوغ

المصدر أو اشتقاق الفعل : حيث يقال

اسم جمع لما دل على الجمع وتخلفت عنه

بعض شروط الجمع. ويفيد مفهوم

الاسمية في مصطلح (( اسم جمع )) أن

الصرفيين قد جعلوا دلالة هذه الكلمة 
وترد همزة اسم الفاعل ((قائل)) مما

يعني أن عين الكلمة حرف متقلب غير ثابت حيث يتردد بين الواو والياء

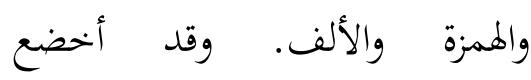
الصرفيون تقلب جنس هذا الحرف وأمثاله لجملة من القوا عد الخاصة التي جمعوها تحت ما يعرف بقواعد الإعلال في العربية فهي من ثم بحموعة قواعد لمعاجلة بعض ما يخرج

$$
\text { 2. عن قواعد الميزان الصري.. }
$$

وهو المنهج الذي يستخدمها

الصرفيون في تحليل بعض الألفاظ التي خرجت عن المنهج الأساسي المتمثل في الوزن الصرفي. ومثال ذلك كما في نهو ((اصطبر)). كماهو المعروف أن في هذا اللفظ خروجا عن قواعد صياغة الكلمة من خلال الوزن الصرفي، إذ بجد حرفا من حروف الزيادة الصرفية في هذه الكلمة متغيرا كذلك. إذ هناك حرف الطاء في كلمة اصطبر وهو مما لا يعد من حروف الزيادة الصرفية التي يجمعها الصرفيون في قولمم "سألتمونيها"، كما أنه ليس من حروف الجذر المعجمي للكلمة ((اصطبر)). وقد قال الصرفيون العرب بأن تاء الافتعال التي تعد من حروف الزيادة الصرفية قد صارت طاء في هذه الكلمة
عد الإعلال التي تقضي بأن تعل لتحرك الياء وانفتاح ما قبلها. إذن إن القول بالقلب المكاني في هذه الحالة، هو الذي يفسر عدم ورود تصريفات أخرى للفعل الماضي ((أيس)) ويسوغ ورود هذا اللفظ على التصحيح مع أن حقه الإعلال وفق قواعد الإعلال الخاصة. واستخدم اللغويون العرب المناهج البديلة بالإضافة إلى المناهج الأساسية والتكميلية ما يلي: 1. منهج الإعلال

يستخدم هذا المنهج في تحليل

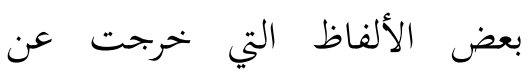
المنهج الأساسي المتمثل في الوزن الصرفي. وذلك كما في نخو لفظ (قل)). كما هو المعروف أن في هذا المثال خروجا على قواعد صياغة الكلمة من حيث الوزن، إذ يرد حرف معجمي في هذا اللفظ على نحو غير مطرد مع أن الأصل وضع جذر واحد في مختلف الأوزان لصياغة كلمات ذوات دلالية صرفية مختلفة. ويعني ذلك : أن الجلذر المعجمي الذي يستخدم في الأوزان الصرفية لمذه الكلمة ونحوها قد جاء متغيرا بكعنى أن بعض حروفه يتقلب، وذلك كما في ألف ((قال)) إذ ترد واوا في المصدر ((قال)) و المضارع ((يقول)) وترد ياء في المني للمجهول ((قيل)) 
اللسان، ولذا ينبغي ألا يدرس منها الدارس إلا القدر

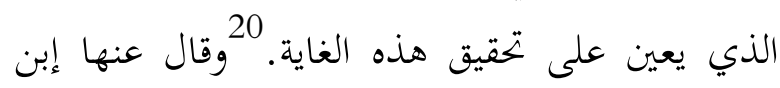
جنى 21:علم الصرف يحتاج إليه جميع أهل العرب أتم حاجة وبهم إليه أشد فاقة لأنه ميزان العربية، وبه نعرف إله

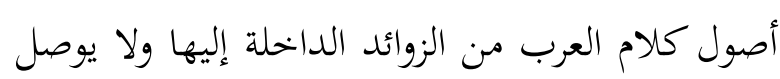
إلى معرفة الإشتقاق إلابه وقد يؤخذ جزء من اللغة كبير

بالقياس، ولايوصل إلى ذلك إلا من طريق التصريف. الاستفادة من علم الصرف لتعليم اللغة

العربية للناطقين بغيرها لابد من تطبيقاته أن يستخذم

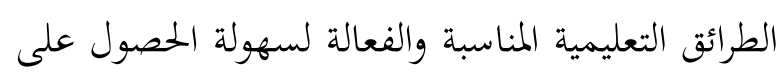
الأهداف المنسودة. وقد وجد محاولة تجريبة كتابة علم الصرف وتعليمه خاصة التصريف في بعض المعاهد الإسلامية و ينقسم إلى التصريف الإصطلاحي حيث

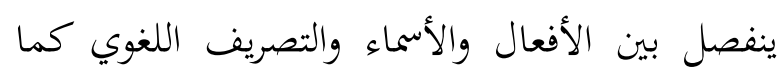

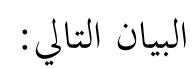

\begin{tabular}{|c|c|c|c|c|c|c|c|}
\hline \multicolumn{4}{|c|}{ أسم } & \multicolumn{3}{|c|}{ فعل } & \multirow[t]{2}{*}{ صيغة } \\
\hline हू & है. & $\bar{C}_{G}$ & $\bar{\zeta}$ & $\underline{\varepsilon}$. & $\stackrel{c}{\widetilde{E}}$ & 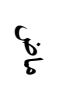 & \\
\hline $8-7$ & 6 & 5 & 4 & 3 & 2 & 1 & \\
\hline 施 & $\xi_{0}^{*}$ & $8^{8}$ & ६.". & 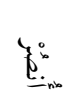 & $0^{\circ}$ & E. & $\vec{c}$ \\
\hline 吝 & $c$ & $i^{*}$ & ६:" & $\hat{q}^{\circ}$ & . & $i$ & $\begin{array}{l}N \\
\stackrel{c}{c}\end{array}$ \\
\hline 离 & G: & $\mathbb{C}_{t}^{*}$ & E: & : & ?: & $r_{6}$ & $\begin{array}{l}w \\
c \\
c\end{array}$ \\
\hline 离 & 产: & $\frac{7 n}{\sigma}$ & $\xi^{\prime \prime}$ & t.0 & 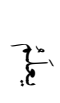 & 究 & $\underset{c}{t}$ \\
\hline 㑷 & 1 & $\frac{c \cdot b}{4: 5}$ & 童" & 集: & :ib & 舟 & ورن \\
\hline
\end{tabular}

20 حسن شحاتة، تعليم اللغة العربية بين النظرية و النطبيق. الدار المصرية اللبنانية: القاهرة. 1993م. صحاتة، تعليم اللفة العبية لين 201 21 حاتم صالح الضامن،الصرف................. 15
ونحوها. وقد أخضع الصرفيون تقلب

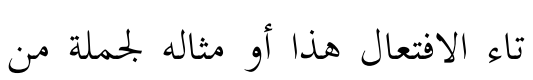

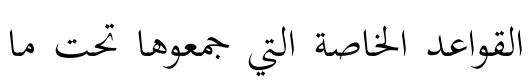
يعرف بقواعد الإ بدال، فهي بجموعة قواعد ثانية لمعالجة ما يخرج عن قواعد

$$
\text { الميزان الصرفي. }
$$

ويرجع التفرق بين هذين النمطين

غير الأساسيين إلى عدم خروج النمط النعرف بين الأول من إطار القواعد والقوانين الصرفية بخلاف الثاني الذي يعتمد على التفسير الفونولوجي. ويمكن إعادة عرض مناهج التحليل وفقا لهذا

$$
\text { على النحو التالي: }
$$

الاستفادة من علم الصرف لتعليم اللغة العربية

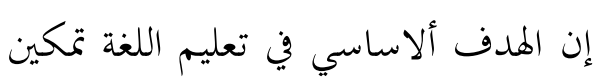

المتعلم من فهم التعبير السليم الواضح الذي يستمع

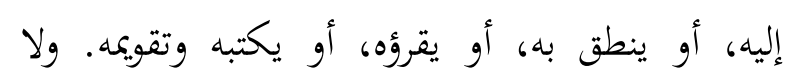

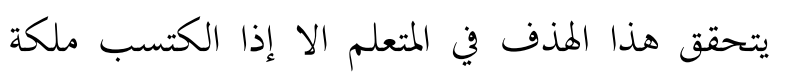

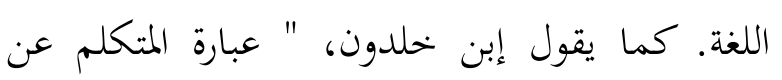
مقصوده. وتلك العبارة فعل لساني، فلابد أن تسير إنين ملكة متقررة في عضو الفاعل لها وهي اللسان. 18. وأضاف إليه على 19،" إن الغرص من تعليم القواعد هو

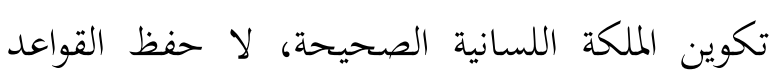
البحردة. وليست القواعد غاية تقصد لذاتها، ولكنه وسيلة إلى ضبط الكام وتصحيح الأساليب، وتقويم

إبن خلدون، مقدمة إبن خلدون، دار القلم، يروت:لبنان. ط 1، 1978م. ص. nم 546 19 على أمد مدكور، تدريس فنون اللغة العربية، دار الفكر العرب: قاهرةز

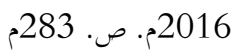


المزيدة، والصحيحة من المعتلة مع معانيها

المضمونة وتطبيقاها في الجمل المفيدة.

3- إن دراسة الصرف يجب أن تكثر وتعالج

طريقة التدريب العملي دون حاجة إلى كثرة

شرح قواعدها وتنسئوظيفتها الأساسية.

مثال أ: حضرطالب في الفصل / ميكضر طالب في

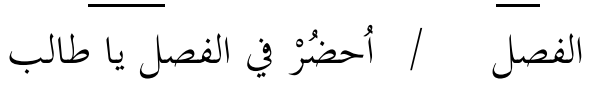

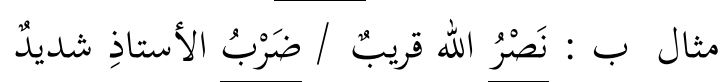
كتابَةُ أحْسَنْ جَيِّدُ

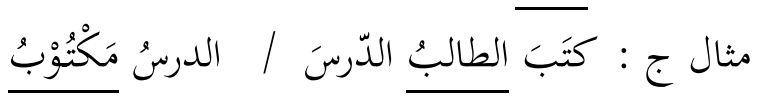

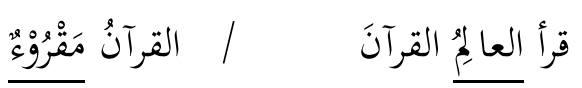

الخحاتمة

إنطلاقا مما بحثه الباحثون مما يتعلق بعلم

$$
\text { الصرف قدم الخلاصة التالية: }
$$

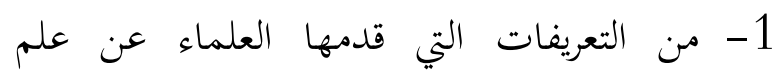

الصرف نستطيع أن نلخص أن الأهداف من فن عن عن أنماء

تعليم الصرف هي : الدرس عن تحويل الكلمة

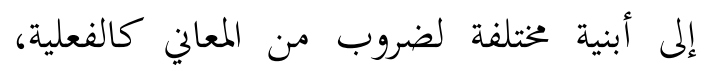

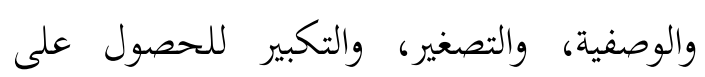

معان مقصودة لا تحصل إلا بها.

2- تطور علم الصرف في أربع مراحل وهي: (1)

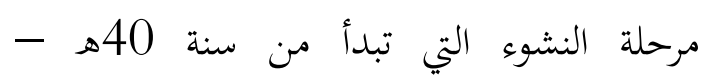

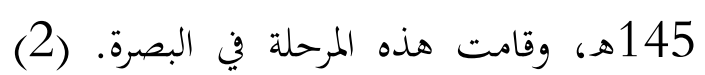

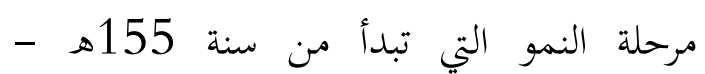

220هـ، و قامت هذه التي تبدا هن المرحلة في البصرة

والكوفة. (3) مرحلة النهوض والكمال التي تبدأ

من سنة 221هـ - 292هـ، وقامت هذه وحلة النهال

المرحلة أيضا في البصرة و الكوفة. (4) مرحلة

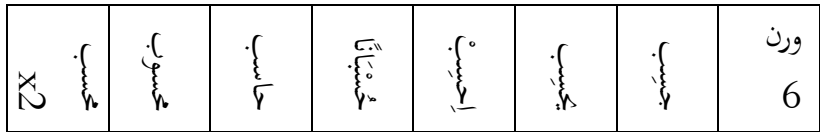

التصريف الاصطلاحي عند على معصوم كرابياك)

2) التصريف اللغوي :

\begin{tabular}{|c|c|c|c|c|c|c|}
\hline \multicolumn{6}{|c|}{ الفعل الماضي } & الضما \\
\hline رَضِيَ & رَمَنْ & باعَ & قالَ & مَدَّ & نصَرَ & هو \\
\hline رضِيًا & رَرَيًَا & باعًا & قالا & مدَّا & نصرًا & L \\
\hline رضوُوا & رمَوْا & باعُوا & قالوُا & مدُُوْا & نصرَرْوا & هم \\
\hline رَضِيَتْ & رمَتْْ & باعَتْ & قالَتْ & مدَّتْْ & نصَرَتْ & هي \\
\hline رَضِيَتَا & رَرَتًَا & باعًَا & قالًَا & ملَّتًَا & نصرَرًَا & ه \\
\hline رضِينَ & رَرَيْنَ & بِعْنَ & قُلْنَ & مَدَدْنَ & نَصَرْنَ & هُنّ \\
\hline رَضِيْتَ & رَرَيْتَ & لِعْتَ & قُلْتَ & مَدَدْتَ & نَصَرْتََّ & أنت \\
\hline رَضِيْتُمَا & رَرَمَيْتُمَا & بِعْتُمَا & قُلْتُتْمَا & مَدَدْتُمَا & نَصَرَتُمًَا & أنتما \\
\hline رَضِيْتُمْ & رَرَيْتُمْ & بِعْتُمْ & قُلْنَمْم & مََدَدْتُمْ & نَصَرَرْمُهُ & أنتم \\
\hline رَضِيْتِ & رَرَيْنِ & بِعْبِ & قُلْتِ & مَدَدْتِ & نَصَرْتِ & أنتِ \\
\hline رَضِيْتُمَا & رَرَيْتُمَا & بِعتتُمَا & قُلْتُمَا & مَدَدْتُمَا & نَصَرَتُمْا & أنتما \\
\hline رَضِيْيُنَّ & رَرَمَيْتُنَّ & بِعْتَنَّ & قَلْنَنُّ & مَدَدْتُنُّن & نَصَرَتُتُنَّ & أنتن \\
\hline رَضِيْتُ & رَرَيْتُْ & بِعْتُ & قُلْتُ & مَدَذْتُ & نَصَرْتُ & أنا \\
\hline رَضِيْنَا & رَرَمَيْنَا & بِعْنَا & قُقلنَا & مَدَدْنَا & نَصَرْنَا & نحن \\
\hline
\end{tabular}

(صورة التصريف اللغوي عند أصف مرتضى باندونج) انطلاقا مما سبق ذكره رأى الباحثون أن لتعليم

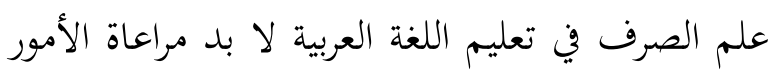
التالية : 1- أن تعليم علم الصرف ليس هادفا بل وسيلة

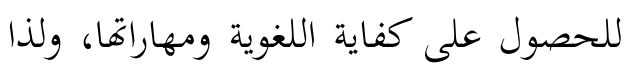
الاتجاه في أبواب الصرف إلى الناحية العملية

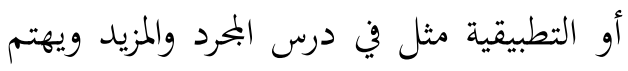
بتدريب الدارس الكثير على الانتفاع في معرفة

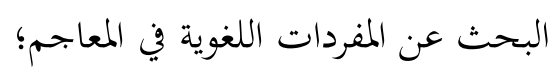

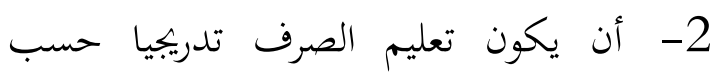

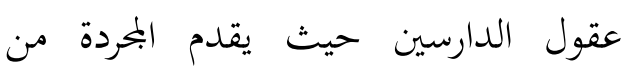


تمام حسان، مناهج البحث في اللغة. دار الثقافة دار

$$
\text { البيضاء: المغربز 1979م. }
$$

حاتم صالح الضامن، الصرف. مركز جمعة الماجد الثاقفة

$$
\text { والتراث. دبي. 2001م. }
$$

حسان بن عبد الله الغنيمان، الواضح في الصرف. مالك بن سعود مكة المكرومة دون السنة.

حسن شحاتة، تعليم اللغة العربية بين النظرية و التطبيق. الدار المصرية اللبنانية: القاهرة.

$$
\text { 1993 }
$$

حسن هيداوي، مناهج الصرفيين ومذاهبهم في القرن الثالث والرابع من الهجرة. دار القلم: دمشق.

شوقي ضيف، المدارس النحوية، دارق المعارف،

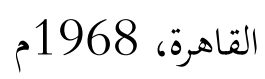

عبده الراجحي. التطبيق الصرفي، دار المعرفة الجامعية:

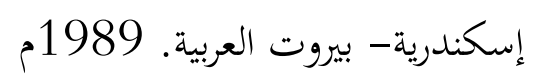

على أحمد مدكور، تدريس فنون اللغة العربية، دار

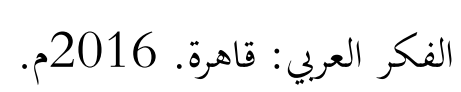

عمر بن ثابت الثمانيني، شرح التصريف، تحقيق الدكتور إبراهيم بن سليمان البعيمي، ط. 1.

$$
\text { مكتبة الرشد: الرياض. 1419هـ. }
$$

لطيفة إبراهيم النجاري، دور البيئة الصرفية وصف الظاهرة النحوية وتقعيدها: دار البشر: عمان

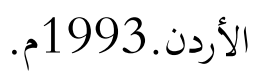

محمد عبد العزيز عبد الدايم، النظرية اللغويةفيالتراث العربي. دار السلام : القاهرة. 2006م.
الترجيح التي تبدأ من سنة 293هـ - عصرنا

الحاضر. نشأت هذه المرحلة في بغداد تمخ تنزعت من أقطار العالم الإسلامي. تتكون نظريات علم الصرف من النظربة الصرفية ومناهج النظرية الصرقية للتحليل. النظرية الصرفية تتكلم عن أصالة الصيغ وفرعيتها مع نماذجها وتطبيقات نماذجها. وأما مناهج النظرية الصرقية للتحليل فتتكلم عن المناهج الأساسية وغيرها. 3- الاستفادة منه لتعليم اللغة العربية هي أن علم الصرف نوع من قواعد اللغة العربية وله وظيفته المهمة في تعليم اللغة العربية. وليس تعليم علم الصرف هدفا لذاته ولكنه وسيلة إلى المهارات اللغوية، ولذا ينبغي ألا يدرس الدارس منه إلا القدر الذي يعين على تحقق الهدف.

قائمة المراجع والمصادر ابن جنى، الخصائص، عالم الكتب:بيروتز ط. 3. 1983 ابن خلدون، مقدمة إبن خلدون، ، دار القلم، بيروت:لبنان. ط 1، 1978م 197. إبن مالك، شرح الكافية الثافية. تحقيق الدكتور عبد

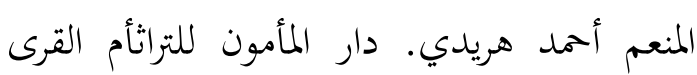
مكة المكرمة. 1402هـ إبن منظور، لسان العرب (صرف) 91:11. دار المعارف، دون السنة. أبو الحسن علي بن هشام الكيلاني، شرح الكيلاني لنصريف العزي، دس. 